\title{
CSMJ
}

\section{Filtration Face Mask 3-induced Anaphylaxis in a Healthcare Worker During the COVID-19 Pandemic: A Case Report}

\author{
(D) Sultan Özselçuk, (D) Ramazan Güven, (D) Banu Arslan
}

University of Health Sciences Turkey, Başakşehir Çam and Sakura City Hospital, Clinic of Emergency, İstanbul, Turkey

What is known on this subject?

Nothing is known about this subject.

\begin{abstract}
What this study adds?
This case shows the importance of using good quality materials to produce facial masks for the health of health care providers as well as for the people. Using poor-quality materials or unchecked products can cause life-threatening problems for consumers.
\end{abstract}

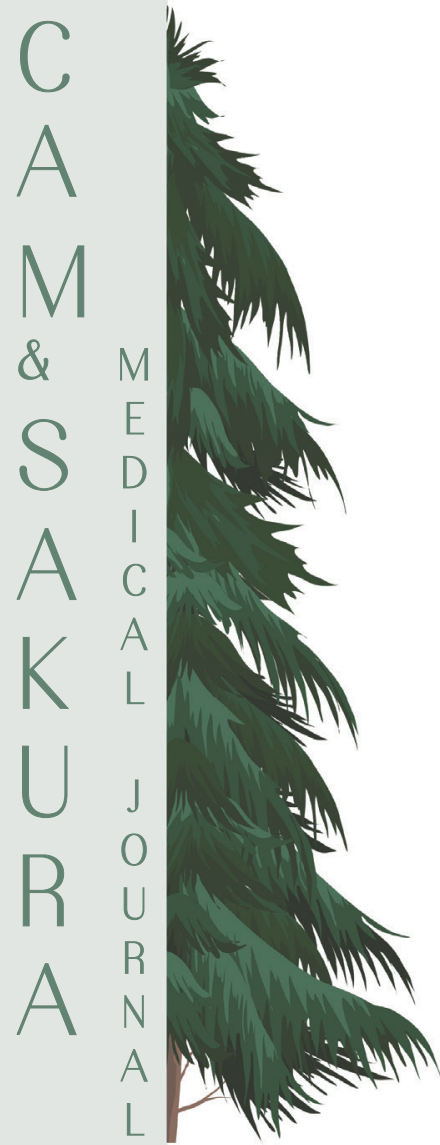

\section{ABSTRACT}

This study aimed to focus on using high quality personal protective equipment (PPE). Low quality PPE usage can cause life-threatening problems for health care workers and public health. The coronavirus disease-2019 pandemic has led to a substantial increase in the usage of face mask wordwide. Fabric, surgical, N95, filtration face mask 2 (FFP2), and FFP3 masks are used to avoid the increased risk of transmission. These masks directly contact the skin; therefore, they may cause the inhalation of the filtration fibers on the mask. Thus, the materials and methods used in mask production are an important public health concern. A 37-year-old healthcare worker was admitted to the emergency department with shortness of breath and cough after wearing an FFP3 mask for an hour. The patient presented with following vital signs: Oxygen saturation $\left(\mathrm{SpO}_{2}\right)$ of $89 \%$, heart rate of 120 beats/min, blood pressure of $89 / 60 \mathrm{mmHg}$, and respiratory rate of 25 breaths/min. Stridor and bilateral wheezing were noted on physical examination. Considering that the patient developed an anaphylactic reaction due to the fiber material on the inner surface of the mask worn by the patient, anaphylaxis treatment was administered. Following the treatment, patient's clinical status had improved and $\mathrm{SpO}_{2}$ reached up to $98 \%$. The patient had a history of atopy; therefore, antihistamines were prescribed and dietary modifications were recommended. We report the first case of anaphylactic reaction in a healthcare worker, resulting from the fiber part of a face mask. When foreign body aspiration is suspected, the possibility of anaphylactic reaction to the aspirated material should also be considered. Our case emphasizes that before using face masks, the inner surface should be checked and it must be intact. Additionally, people with the history of atopy should be more careful in selecting the materials used in masks; they should carefully examine the product they bought. Being competent and careful in the controls during the production phase has a great importance in protecting the lives of healthcare workers. Keywords: Anaphylaxis, FFP3 mask, personal protective equipment, dyspnea 


\section{Introduction}

Anaphylaxis is a severe multi-systemic reaction that occurs within minutes of exposure to an allergen (1). It is classified into allergic and non-allergic anaphylaxis. Allergic anaphylaxis is mediated by immunologic mechanisms, whereas non-allergic anaphylactic reaction is triggered by other mechanisms. However, the clinical diagnosis and management for both are identical. All systems and organs can get affected during anaphylaxis, especially the cutaneous, respiratory, cardiovascular, and gastrointestinal systems (Table 1) $(2,3)$.

The cause of anaphylaxis varies across the regions and societies; however, the most common causes of anaphylactic reactions include foods, drugs, and insect bites (4).

The acute management of anaphylaxis involves airway stabilization, adequate oxygenation, and decontamination. Epinephrine is the first-line of treatment for anaphylaxis. If hypotension or tachycardia is present, fluid resuscitation with intravenous crystalloids should begin immediately. Steroids and antihistamines are usually recommended as the secondline of treatment. Selective bronchodilators (salbutamol) are used for allergic bronchospasm and magnesium therapy for resistant bronchospasm (4).

Due to the coronavirus disease-2019 (COVID-19) pandemic, the use of face masks has increased worldwide to reduce transmission by droplets (5). Enormous global demand for face masks has led to a dramatic increase in the production over a very short period. This rapid change raises some quality concerns because these masks have a direct contact with skin and indirect contact with airway. Errors that may occur in the production of masks on their inner surface can lead to lifethreatening consequences.

This study aimed to focus on using high quality personal protective equipment (PPE). Low quality PPE usage can cause life-threatening problems for health care workers and the public.

\begin{tabular}{|c|c|}
\hline System & Signs and symptoms \\
\hline Respiratory & $\begin{array}{l}\text { Rhinitis, pharynx edema, laryngeal } \\
\text { edema, cough, bronchospasm, and } \\
\text { dyspnea }\end{array}$ \\
\hline Cardiovascular & Dysrhythmia, collapse, and cardiac arrest \\
\hline Cutaneous & Itching, urticaria, angioedema, and rash \\
\hline Gastrointestinal & $\begin{array}{l}\text { Nausea, vomiting, cramping, and } \\
\text { diarrhea }\end{array}$ \\
\hline Ocular & Itching, tears, and redness \\
\hline Genitourinary & Urgency and cramping \\
\hline
\end{tabular}

\section{Case Report}

A 37-year-old female healthcare worker presented to the emergency department (ED) with shortness of breath and cough after wearing an FFP3 mask for an hour. She did not take any medication, ate something strange, or wore something new that could cause anaphylaxis before being admitted to the ED. She had a history of atopy and latex allergy.

Upon arrival, the patient was awake, cooperative, and oriented. Mild respiratory distress was noted. The patient's vital signs were oxygen saturation $\left(\mathrm{SpO}_{2}\right)$ of $89 \%$, heart rate (HR) of 120 beats/min, blood pressure of $89 / 60 \mathrm{mmHg}$, and respiratory rate of 25 breaths/min. The physical examination revealed a normal review of systems, except for tachypnea, bilateral wheezing, and stridor on inspiration. No rash, angioedema, cyanosis, and foreign body in the oropharynx were seen on initial examination.

The patient's face mask examination revealed a defective inner surface and a piece of fiber that protruded from the midline (Figure 1, 2).

The patient's progressive airway obstruction was treated with $5 \mathrm{~L} / \mathrm{min}$ of oxygen therapy through a non-rebreather mask. For hypotension and progressive airway obstruction, $0.5 \mathrm{mg}$ of adrenaline was immediately administered intramuscularly through the left vastus lateralis femoris. Resuscitative efforts also involved $80 \mathrm{mg}$ of prednisolone, 45.5 $\mathrm{mg}$ of pheniramine, and 3 doses of salbutamol inhaler.

Following these treatments, the patient showed dramatic clinical improvement with no signs of respiratory distress and tachycardia. $\mathrm{SpO}_{2}$ reached up to $98 \%$ and $\mathrm{HR}$ became 80 beats/min. After monitoring the patient for 8 hours, she was

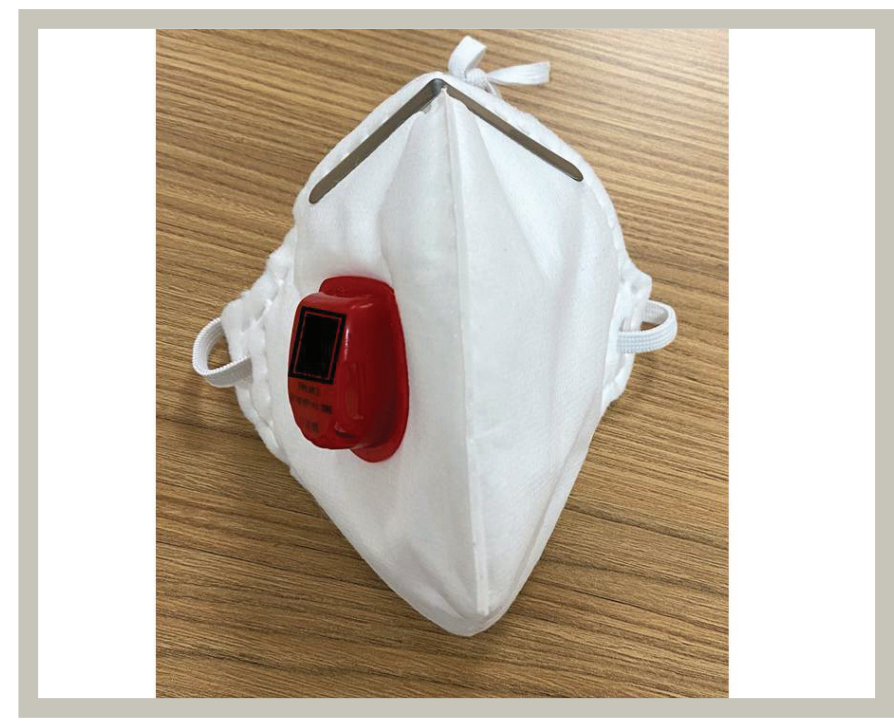

Figure 1. Surface of mask 


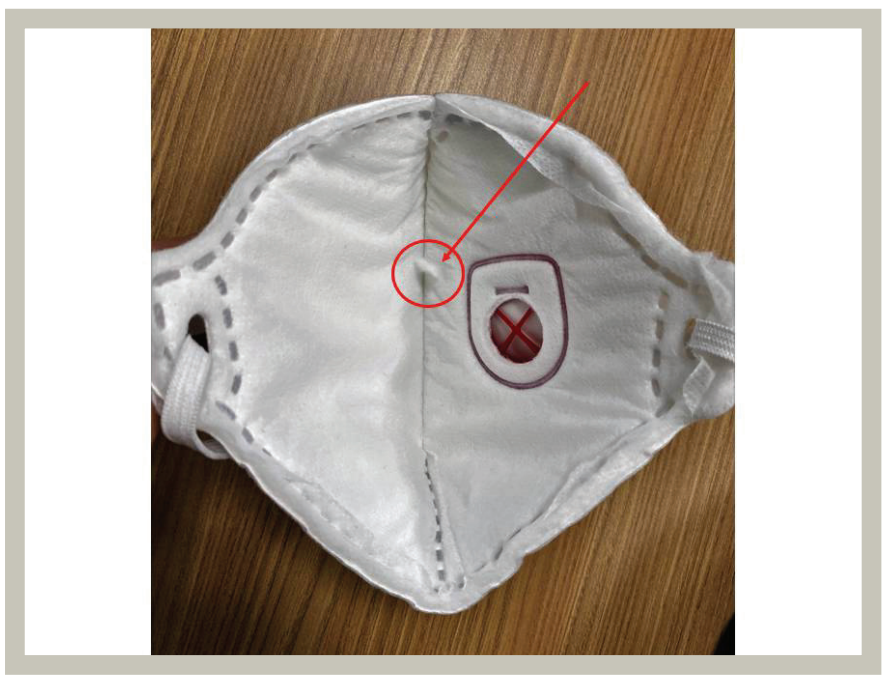

Figure 2. Innerface of mask

discharged with an antihistamine and dietary modifications were recommended.

\section{Discussion}

Anaphylaxis can occur from a variety of substances such as foods, medications, and insect bites. Some medical products may pose a risk as an important allergen for healthcare workers. Healthcare workers are at a higher risk for developing latex allergies. Latex allergy is reported to be present in $12 \%$ of healthcare workers (6). Another study in 2014 revealed that $4.8 \%$ of healthcare workers in Turkey have latex allergy (7).

Face mask-induced contact dermatitis has been reported in the medical literature with increasing numbers during the COVID-19 pandemic. A study conducted in China reported a patient who developed contact dermatitis due to the sponge band on the nose of the FFP2 mask (8).

According to a study conducted among healthcare professionals, 39.5\% of patients using PPE were reported to have irritant contact dermatitis, and the most common causes were glasses (51\%), N95 masks (30.77\%), and face protectors (17\%). Nasal dorsum and cheeks have been reported as the most affected anatomical areas (9).

Another study reported an increasing number of contact dermatitis among healthcare workers caused by frequent hand wash, prolonged use of latex gloves, and usage of disinfectant during the COVID-19 pandemic.

In medical literature, anaphylactic reaction due to fiber material of a face mask has not been reported yet (10).

A detailed statement of written patient consent was signed by the patient for case presentation.

We reported the first case of anaphylactic reaction that resulted from the fiber part of a face mask in a healthcare worker. When foreign body aspiration is suspected, the possibility of anaphylactic reaction to the aspirated material should also be considered. Our case emphasizes that before using face masks, the inner surface should be checked and it must be intact. In addition, people with a history of atopy should be more careful in selecting the materials used in masks and should carefully examine the product they bought. Being competent and careful in the controls during the production phase is of great importance in terms of protecting the lives of healthcare workers.

\section{Acknowlegement}

The authors appreciate kind support of Basakşehir Çam and Sakura City Hospital, Department of Emergency Medicine.

\section{Ethics}

Informed Consent: The patient's consent and sgnature taken with hand writing.

Peer-review: Externally and internally peer-reviewed.

\section{Authorship Contributions}

Surgical and Medical Practices: S.Ö., R.G., B.A., Concept: S.Ö., R.G., B.A., Design: S.Ö., R.G., B.A., Data Collection or Processing: S.Ö., R.G., B.A., Analysis or Interpretation: S.Ö., R.G., B.A., Literature Search: S.Ö., R.G., B.A., Writing: S.Ö., R.G., B.A.

Conflict of Interest: No conflict of interest was declared by the authors.

Financial Disclosure: The authors declared that this study received no financial support. 


\section{REFERENCES}

1. Tupper J, Visser S. Anaphylaxis: A review and update. Can Fam Physician 2010;56:1009-1011.

2. Lane RD, Bolte RG. Pediatric anaphylaxis. Pediatr Emerg Care 2007;23:49-56; quiz 57-60.

3. Tintinalli JE, Cline DM, American Collage of Emergency Physicians; McGraw-Hill Companies, et al. Tintinalli's emergency medicine : just the facts. McGraw Hill: 2013; p:177-181.

4. Doğru M, Bostancı İ. Anafilaksi ve Anafilaksideki Gelişmeler. Çocuk Dergisi 2011;11:43-53.

5. Cherry JD. The role of face protection for respiratory viral infections: a historical perspective. J Pediatric Infect Dis Soc 2020;9:411-412.

6. Lieberman P, Nicklas RA, Oppenheimer J, et al. The diagnosis and management of anaphylaxis practice parameter: 2010 update. J Allergy Clin Immunol 2010;126:477-480.e1-42.
7. Wu M, McIntosh J, Liu J. Current prevalence rate of latex allergy: why it remains a problem? J Occup Health 2016;58:138-144.

8. Xie Z, Yang YX, Zhang H. Mask-induced contact dermatitis in handling COVID-19 outbreak. Contact Dermatitis 2020;83:166-167.

9. Singh M, Pawar M, Bothra A, et al. Personal protective equipment induced facial dermatoses in healthcare workers managing Coronavirus disease 2019. J Eur Acad Dermatol Venereol 2020;34:e378-e380.

10. Erdem Y, Altunay IK, Aksu Çerman A, et al. The risk of hand eczema in healthcare workers during the COVID-19 pandemic: do we need specific attention or prevention strategies? Contact Dermatitis 2020;83:422-423. 